\title{
PAPER KindS AND THE EFFECTIVENESS OF THE Phases of the Prints Recycling Process
}

\author{
BolancA Mirkovic, I. \& BOLANCA, Z.
}

Abstract: Recycled fibres have become an important source in the paper production. In this work the investigation results of the influence of the paper kinds and different inks on the effectiveness of the phases of the recycling process have been presented. The results were discussed in regard to the paper kind, the grammage and coating as well as detaching of the ink from the printing substrate in the disintegration phase and the removal from the suspension in the flotation process. Somewhat greater fragmentation and smaller recycling effectiveness of the prints made with the ink with greater part of the renewable raw material have been proved. The obtained results of handsheet brightness and the mechanisms of the ink detaching process are confirmed and explained by the distribution of the ink number per classes of sizes and by the surface they occupy on the handsheet in different phases of the paper recycling process.

Key words: mat fine art paper, fglossy ine art paper, offset paper, recycled paper, grammage, coating, recycling, disintegration, flotation, image analysis, brightness
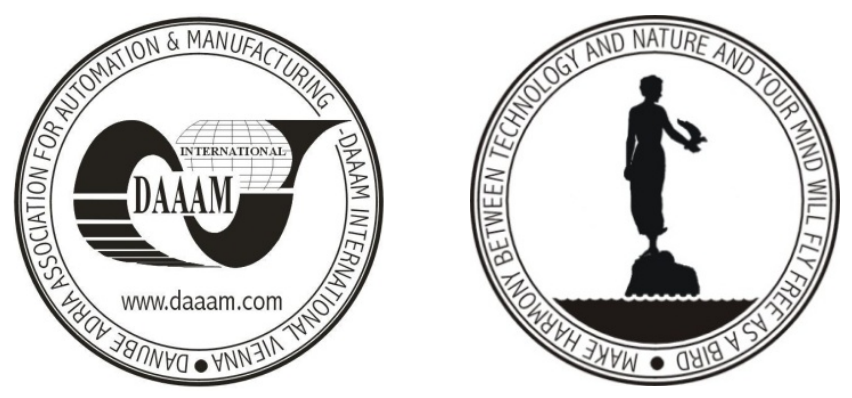

Authors' data: Dr. Bolanca Mirkovic, I[vana]; Prof. Bolanca, Z[denka], University of Zagreb, Faculty of Graphic Arts, Getaldiceva 2, 10000, Zagreb, ivana.bolanca@grf.hr, zbolanca@grf.hr

This Publication has to be referred as: Bolanca Mirkovic, I[vana] \& Bolanca, $Z$ [denka] (2008). Paper Kinds and the Effectiveness of the Phases of the Prints Recycling Process, Chapter 10 in DAAAM International Scientific Book 2008, pp. 111-124, B. Katalinic (Ed.), Published by DAAAM International, ISBN 978-3901509-66-7, ISSN 1726-9687, Vienna, Austria

DOI: $10.2507 /$ daaam.scibook.2008.10 